In conclusion, the IP-10 test performs with equal sensitivity to the QFT-IT in a TB/HIV-endemic setting. Combining the tests significantly improves sensitivity, even in HIV-positive patients. The IP-10 test seems less affected by a low CD4 cell count than the QFT-IT. Further approaches for improvement of TB diagnosis are needed, especially in TB/HIV-endemic settings, and the IP-10 biomarker represents a promising example.

M.G. Aabye ${ }^{*, * *}$, M. Ruhwald****, G. PrayGod ${ }^{\#}$, K. Jeremiah ${ }^{\# \text {, }}$ M. Faurholt-Jepsen ", D. Faurholt-Jepsen ", N. Range ${ }^{+}$, H. Friis ${ }^{\Uparrow}$, J. Changalucha", A.B. Andersen ${ }^{\S}$ and P. Ravn ${ }^{f}$ ${ }^{*}$ Clinical Research Center, University of Copenhagen, Hvidovre Hospital, Hvidovre, "Dept of Human Nutrition, Faculty of Life Sciences, University of Copenhagen, Frederiksberg, ${ }^{5}$ Dept of Infectious Diseases, University of Copenhagen, Rigshospitalet, Copenhagen, and ${ }^{f}$ Unit for Infectious Diseases, University of Copenhagen, Herlev Hospital, Herlev, Denmark. "National Institute for Medical Research, Mwanza Medical Research Centre, Mwanza, and ${ }^{+}$National Institute for Medical Research, Muhimbili Medical Research Centre, Dar Es Salaam, Tanzania. **Both authors contributed equally to the study.

Correspondence: M.G. Aabye, Clinical Research Centre, University of Copenhagen, Hvidovre Hospital, Kettegaard Alle 30, 2650 Hvidovre, Denmark. E-mail: martine@aabye.com

Support Statement: Data from this study were presented, in part, at the 2nd Global Symposium on IGRAs, (Dubrovnik, Croatia; 2009), the European Respiratory Society 19th Annual Congress, (Vienna, Austria; 2009) and the 17th Conference on Retroviruses and Opportunistic Infections (CROI) (New Orleans, LA, USA; 2010).

Statement of Interest: Statements of interest for M.G. Aabye, M. Ruhwald and P. Ravn, and the study itself can be found at www.erj.ersjournals.com/site/misc/statements.xhtml
Acknowledgements: The authors would like to thank all colleagues contributing to this project, including the staff at the National Institute for Medical Research (NIMR) Mwanza Centre, Sekou Toure Regional Hospital, Buzuruga Health Centre, Bugando Medical Centre and Butimba Health Centre (all Mwanza, Tanzania), especially laboratory technician O. Kaswamila (NIMR Mwanza Centre). Equally, the authors thank the staff at the Laboratory for Infectious Diseases at University of Copenhagen, Hvidovre Hospital (Hvidovre, Denmark) and at the AIDS Laboratory at University of Copenhagen, Rigshospitalet (Copenhagen, Denmark) for their collaboration, as well as R. Wallis (Pfizer, New London, CT, USA) for his helpful comments and critique.

\section{REFERENCES}

1 World Health Organisation. Global tuberculosis control: epidemiology, strategy, financing. Geneva, WHO, 2009.

2 Domínguez J, Latorre I, Altet $\mathrm{N}$, et al. IFN- $\gamma$-release assays to diagnose TB infection in the immunocompromised individual. Expert Rev Resp Med 2009; 3: 309-327.

3 Aabye MG, Ravn P, PrayGod G, et al. The impact of HIV infection and CD4 cell count on the performance of an interferon gamma release assay in patients with pulmonary tuberculosis. PLOS ONE 2009; 4: e4220.

4 Kabeer BS, Sikhamani R, Raja A. Comparison of interferon gamma and interferon gamma-inducible protein-10 secretion in HIVtuberculosis patients. AIDS 2010; 24: 323-325.

5 Ruhwald M, Bodmer T, Maier C, et al. Evaluating the potential of IP10 and MCP-2 as biomarkers for the diagnosis of tuberculosis. Eur Respir J 2008; 32: 1607-1615.

6 Ruhwald M, Petersen J, Kofoed K, et al. Improving T-cell assays for the diagnosis of latent TB infection: potential of a diagnostic test based on IP-10. PLOS ONE 2008; 3: e2858.

7 Korpi-Steiner NL, Bates ME, Lee WM, et al. Human rhinovirus induces robust IP-10 release by monocytic cells, which is independent of viral replication but linked to type I interferon receptor ligation and STAT1 activation. J Leukoc Biol 2006; 80: 1364-1374.

8 Lighter J, Rigaud M, Huie M, et al. Chemokine IP-10: an adjunct marker for latent tuberculosis infection in children. Int J Tuberc Lung Dis 2009; 13: 731-736.

9 Syed Ahamed KB, Raman B, Thomas A, et al. Role of QuantiFERONTB gold, interferon gamma inducible protein-10 and tuberculin skin test in active tuberculosis diagnosis. PLoS ONE 2010; 5: e9051.

DOI: $10.1183 / 09031936.00039010$

\title{
New insight into extremely drug-resistant tuberculosis: using atomic force microscopy
}

\section{To the Editors:}

We have recently documented the emergence of new forms of resistant tuberculosis (TB) bacilli (totally drug resistant (TDR)TB or extremely drug-resistant (XXDR)-TB strains) among multidrug-resistant (MDR)-TB patients [1]. XXDR-TB defines any case of TB with resistance to all first- and second-line antiTB drugs whose smears and cultures remain positive despite prolonged therapy [1-3]. At the cellular level of XXDR-TB strains, adaptation was observed and evaluated using transmission electron microscopy (TEM) $[4,5]$. In the exponential phase, three different cell populations were clearly distinguished: one displayed an ordinary pattern $(70-80 \%)$, one exhibited a round or oval shape (15-20\%), and the third displayed an extraordinarily thick cell wall $(21-26 \mathrm{~nm})$ with features similar to stationary or anaerobic dormant bacilli (5$7 \%)[3,4]$. These adapted forms were detected in all XXDR-TB isolates, irrespective of their super families or genotype patterns. We tried to evaluate the different cell population of XXDR-TB strains in comparison to susceptible cells using atomic force microcsopy (AFM). To achieve this goal, we included sputum and culture positive specimens of the same 

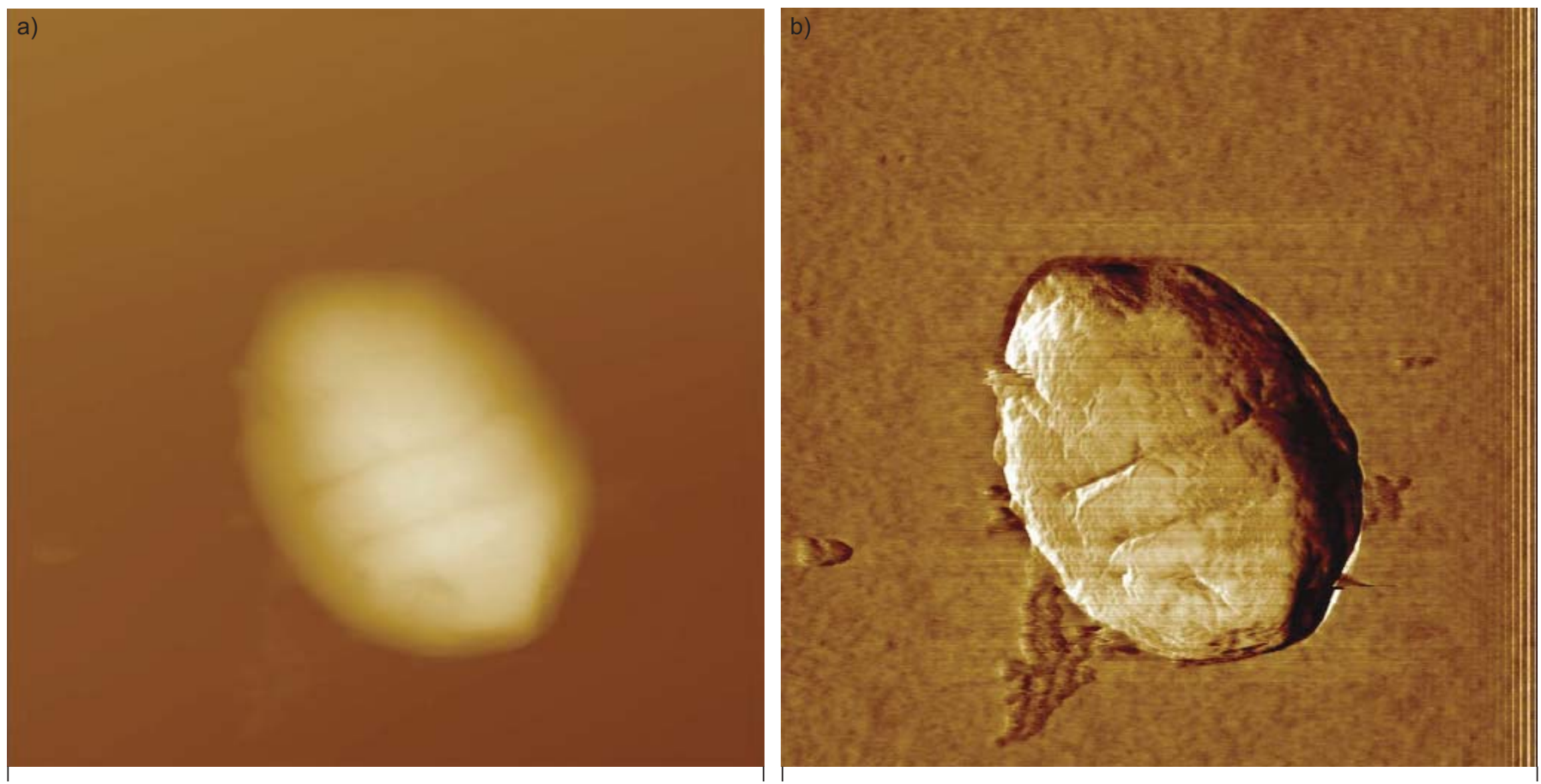

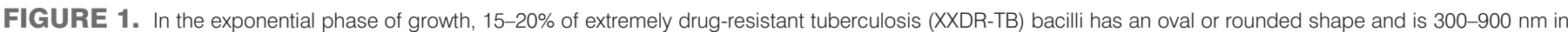
dimension. The average surface roughness of a rod-shaped bacilli was $13.7 \pm 1.5 \mathrm{~nm}$ in comparison to oval XXDR-TB cells which was $10 \pm 0.8 \mathrm{~nm}$ on $200 \times 200 \mathrm{~nm}$.

patients in our study. AFM images were recorded in contact mode using an optical lever microscope equipped with a liquid cell (Nanoscope IV Multimode AFM; Veeco Metrology Group, Santa Barbara, CA, USA) [5]. To image mycobacteria by AFM, the cells were immobilised by mechanical trapping onto isopore polycarbonate membrane (Millipore Corporation, Billerica, MA, USA), with pore size similar to the cell size. After filtering a concentrated cell suspension, the filter was gently rinsed with deionised water, carefully cut $(1 \times 1 \mathrm{~cm})$ and attached to a steel sample puck (Veeco Metrology Group) using a small piece of adhesive tape. The mounted sample was transferred into the AFM liquid cell. Images were recorded in both height and deflection modes; using oxide-sharpened microfabricated Si3N4 cantilevers (microlevers; Veeco Metrology Group) with spring constant of $0.01 \mathrm{~nm}^{-1}[6,7]$. Through AFM observations, we confirmed the existence of oval shaped TB cells among XXDRTB populations (fig. 1). All XXDR-TB bacilli showed prominent ultrastructural alterations (characteristic concentric striations and increased surface roughness) in comparison to susceptible bacilli. The average surface roughness of all adapted XXDR cells
$(14.8 \pm 1.4 \mathrm{~nm}$ on $200 \times 200 \mathrm{~nm}$ height images $)$ was higher than susceptible strains $(8 \pm 2.5 \mathrm{~nm}$ on $200 \times 200 \mathrm{~nm}$ height image) and the differences were statistically significant (table 1). Although not statistically significant, the adapted XXDR rodshaped bacilli with thicker cell wall $(\sim 20-26 \mathrm{~nm})$ revealed a greater surface roughness $(13.7 \pm 2.1 \mathrm{~nm})$ than oval cells $(10 \pm 0.8 \mathrm{~nm})$ (fig. 2). We also noted that our AFM images did not show differences in ultrastructure of the cells isolated from sputum compared to the cell taken from Lowenstein-Jensen culture media. The observed striations and surface roughness in XXDR-TB bacilli were attributed to a direct effect of drugs and were co-related to the mode of arabinogalactan and protein assemblies in the cell wall envelope [8]. Our overall observations were similar to studies by ALTSEENS et al. [8] and VERBELEN et al. [6], who reported that in vitro treatment of native Mycobacterium bovis bacilli Calmette-Guérin with first-line drugs induces the striations and surface roughness. These studies suggest that the efficiency of a given therapy may progressively change with the erosion of the envelope, which may not be in a positive manner. Additionally, in $2-3 \%$ of XXDR-TB bacilli,

TABLE 1 Average surface roughness in susceptible and extremely drug-resistant tuberculosis (XXDR-TB) cells

\begin{tabular}{lccc} 
Type of Mycobacterium tuberculosis bacilli & Cell wall thickness & Length & Average surface roughness on $\mathbf{2 0 0} \times \mathbf{2 0 0} \mathbf{n m}$ \\
\hline & & 1.8 to $3 \mu \mathrm{m}$ & $8 \pm 2.5 \mathrm{~nm}$ \\
Susceptible bacilli & $15.6 \pm 1.3 \mathrm{~nm}$ & 1.8 to $3 \mu \mathrm{m}$ & $10 \pm 0.8 \mathrm{~nm}$ \\
XXDR-TB bacilli: rod like & $20.2 \pm 1.5 \mathrm{~nm}$ & 0.3 to $0.9 \mu \mathrm{m}$ & $12.2 \pm 1.3 \mathrm{~nm}$ \\
XXDR-TB bacilli: round & $19.3 \pm 1.8 \mathrm{~nm}$ & 1.5 to $2 \mu \mathrm{m}$ & $13.7 \pm 2.1 \mathrm{~nm}$ \\
Resistant rod-like bacilli: thick cell wall & $21.8 \pm 6.2 \mathrm{~nm}$ & & \\
\hline
\end{tabular}

Data are presented as the sum of 15-20 steel sample packs that were observed under atomic force microscopy. 

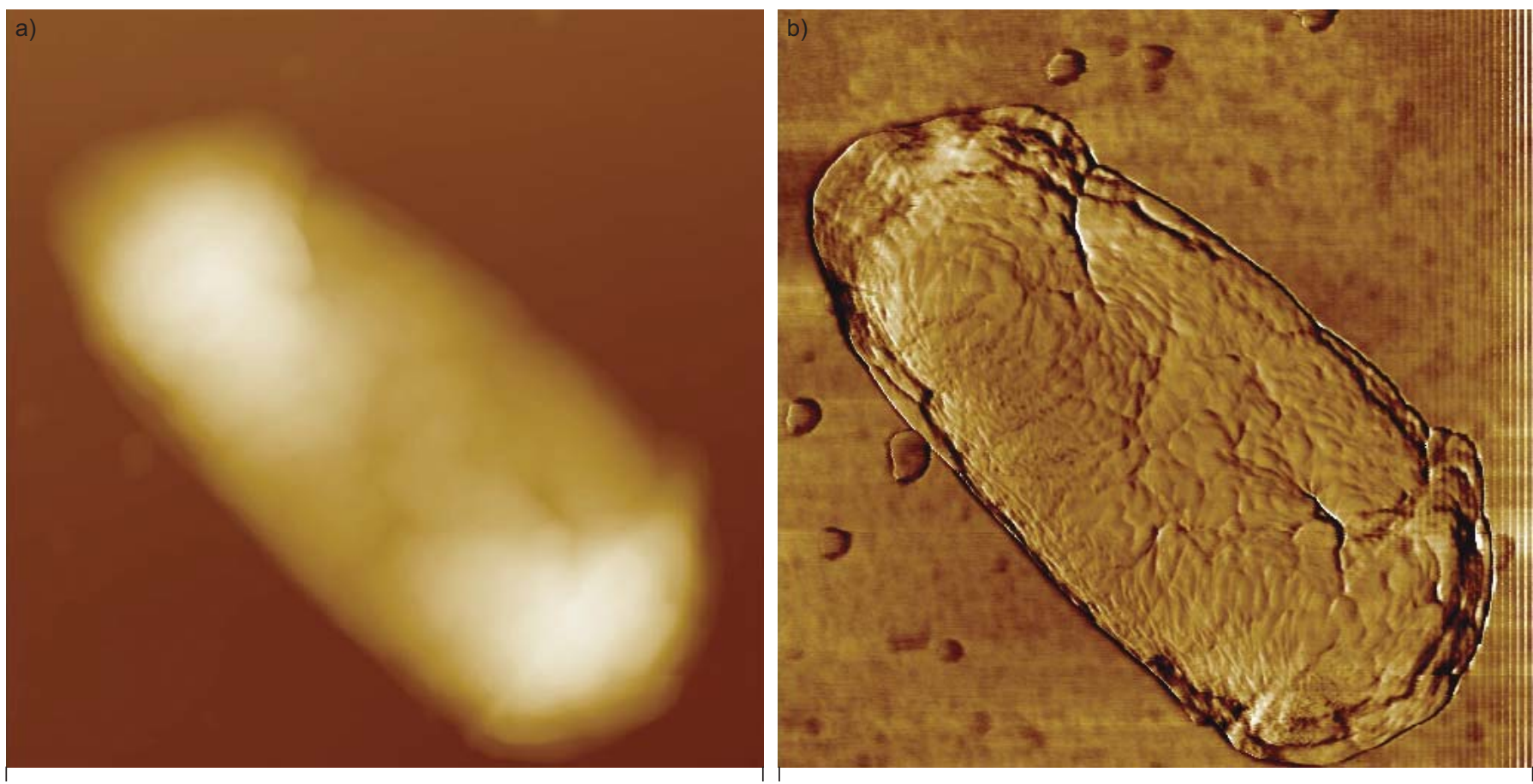

0

$1.70 \mu \mathrm{M} 0$

$1.70 \mu \mathrm{M}$

FIGURE 2. The average surface roughness of all adapted extremely drug-resistant tuberculosis cells was higher (14.8 $\pm 1.9 \mathrm{~nm})$ than susceptible cells $(8 \pm 2.5 \mathrm{~nm})$ and the differences were statistically significant.

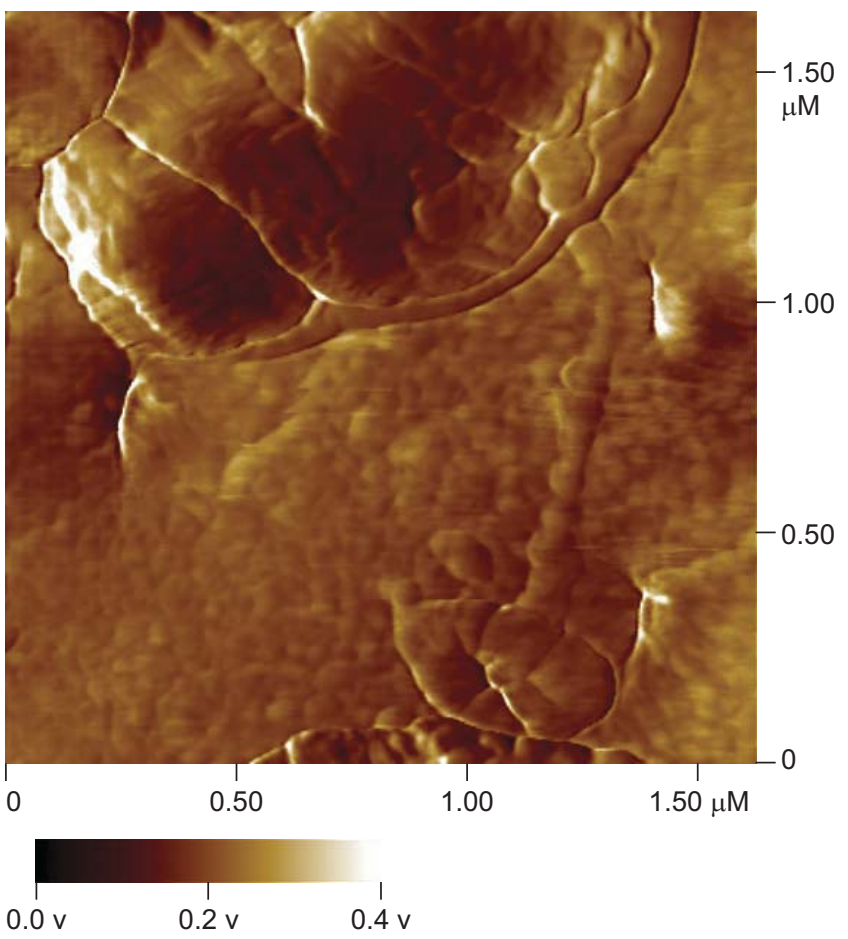

FIGURE 3. Of the extremely drug-resistant tuberculosis (XXDR-TB) bacilli, 2$3 \%$ had elaborated long, tubular extension of the cell envelope (length: $890 \mathrm{~nm}$ to $1 \mu \mathrm{m}$; diameter: $70-75 \mathrm{~nm}$ ), with tapering towards the end. Tubular protrusion had low surface roughness $(2.5 \pm 1.2 \mathrm{~nm})$ in comparison to both the XXDR-TB and susceptible tuberculosis cell envelope. elaboration of long, tubular extensions of the cell envelope (length: $890 \mathrm{~nm}$ to $1 \mu \mathrm{m}$; diameter: $70-75 \mathrm{~nm}$ ), which tapered towards one end, have also been observed (fig. 3). These appendages had very low surface roughness $(2.5 \pm 1.2 \mathrm{~nm})$ in comparison to both XXDR-TB and susceptible-TB cell envelopes. Therefore, we hypothesised that these structures were synthesised by the incorporation of new envelope materials that may comprise inner and outer membranes, peptidoglygcan and periplasmic space. For the first time, these tubular extensions have been seen in Mycobacterium tuberculosis and, at present, we do not know whether they are functional under genetic or environment controls. In our study, the investigated TB strains were isolated from XXDR-TB patients. All patients were subjected to second-line anti-TB drugs for 18-24 months with the following protocols: ofloxacin $\left(400-800 \mathrm{mg} \cdot\right.$ day $\left.^{-1}\right)$; cycloserine $\left(750-1,000 \mathrm{mg} \cdot\right.$ day $\left.^{-1}\right)$; prothionamide $\left(750-1,000 \mathrm{mg} \cdot\right.$ day $\left.^{-1}\right)$; and amikacin $\left(15 \mathrm{mg} \cdot \mathrm{kg}^{-1} \cdot \mathrm{day}^{-1}\right.$ for 5 days per week, maximum $1 \mathrm{~g} \cdot$ day $\left.^{-1}\right)$. Therefore, further investigations are warranted in order to determine whether these morphological changes are induced by the combination therapy or certain specific anti-TB drugs. Finally, our observations have raised three questions. First, could Mycobacteria produce tubular structure on environmental constraints (effect of different drugs and/or low availability of nutrients)? Secondly, are persistent Mycobacteria also capable of producing such appendages? Thirdly, and most importantly, are such passages important for uptake of drugs inside the bacilli? In conclusion, XXDR-TB is a more serious and complex clinical concern than previously appreciated. Thus, urgent strategies are required to speed up novel anti-TB drugs toward resistant bacilli. It is important to understand the possibility of disease transmission through oval shape XXDR-TB bacilli. The size of these bacilli $(300-900 \mathrm{~nm})$ is smaller than rod-shaped bacilli $(1.5-3 \mu \mathrm{m})$ and 
could easily escape attack from the body's immune system. Therefore, if this could happen, then this is an issue requiring urgent attention from the global scientific community.

A.A. Velayati*, P. Farnia*, M.A. Merza*, G.K. Zhavnerko", , P. Tabarsi*, L.P. Titov ${ }^{\#}$, J. Ghanavei ${ }^{+}$, P. Farnia ${ }^{+}$, M. Setare ${ }^{\#}$, N.N. Poleschuyk", P. Owlia ${ }^{\S}$, M. Sheikolslami*, R. Ranjbar ${ }^{\dagger}$ and M.R. Masjedi*

*Mycobacteriology Research Centre, National Research Institute of Tuberculosis and Lung Disease (NRITLD), WHO Collaborating Centre, Shahid Beheshti University, ${ }^{+}$Experimental and Animal research Laboratory, NRITLD, Shahid Beheshti University, ${ }^{f}$ Molecular Biology Research Center, Baqiyatallah University of Medical Sciences, and ${ }^{\S}$ Ministry of Health and Medical Education, Tehran, Iran. "The Republican Research and Practical Centre for Epidemiology and Microbiology, and "Institute for Chemistry of New Materials, Belarus National Academy of Sciences, Minsk, Belarus.

Correspondence: P. Farnia, Mycobacteriology Research Centre, NRITLD/UNION and WHO Collaborative Centre for TB and Lung Diseases, Shahid Beheshti University (Medical Campus), Tehran, 19556, P.O Box 19575/154, Iran. E-mail: pfarnia@hotmail.com

Support Statement: This study was sponsored by a grant from the Ministry of Health and Medical Education, Deputy of Research (2009-2010; Tehran, Iran).

Statement of Interest: None declared.
Acknowledgements: The authors wish to thank the staff of the Microbiology Unit at the Republican Research and Practical Centre for Epidemiology and Microbiology (Minsk, Belarus). We are also sincerely thankful to the TB laboratory staff at the Mycobacteriology Research Centre/NRITLD (Tehran, Iran).

\section{REFERENCES}

1 Velayati AA, Masjedi MR, Farnia P, et al. Emergence of new forms of totally drug-resistant tuberculosis bacilli: super extensively drugresistant tuberculosis or totally drug resistant strains in Iran. Chest 2009; 136: 420-425.

2 Migliori GB, De Iaco G, Besozzi G, et al. First tuberculosis cases in Italy resistant to all tested drugs. Euro Surveill 2007; 12: 20.

3 Migliori GB, Loddenkemper R, Blasi F, et al. 125 years after Robert Koch's discovery of the tubercle bacillus: the new XDR-TB threat. Is "science" enough to tackle the epidemic? Eur Respir J 2007; 29: 423-427.

4 Velayati AA, Farnia P, Masjedi MR, et al. Totally drug-resistant tuberculosis starins: evidence of adaptation at the cellular level. Eur Respir J 2009; 34: 1-3.

5 Velayati AA, Farnia P, Masjedi MR, et al. Differences in cell wall thickness between resistant and non resistant of Mycobacterium tuberculosis: using transmission electron microscopy. J Chemother 2009; 55: 303-307.

6 Verbelen C, Dupres V, Menozzi FD, et al. Ethambutol-induced alterations in Mycobacterium bovis BCG imaged by atomic force microscopy. FEMS Microbiol Lett 2006; 264: 192-197.

7 Kasas S, Ikai A. A method for anchoring round shaped cells for atomic force microscope imaging. Biophys J 1995; 68: 1678-1680.

8 Alsteen D, Verbelen C, Dague E, et al. Organization of the mycobacterial cell: a nanoscale view. Pflugers Arch 2008; 456: 117-125. 